\title{
Etiologies of Bacterial Meningitis in Context of Conflict in Central African Rural Areas
}

\author{
Gaspard Tékpa ${ }^{1,6,}$, , Alain Farra ${ }^{2}$, Eudes Gbangba-Ngaï ${ }^{3,6}$, Clotaire Rafaï ${ }^{4}$, Jean De Dieu Longo ${ }^{6}$, \\ Fidèle Kitakossi ${ }^{1}$, Pascal Mbelesso ${ }^{5,6}$
}

${ }^{1}$ Department of Infectious Diseases, Hôpital de l'Amitié, Bangui, Central African Republic

${ }^{2}$ Department of Mycobacteriology, Institut Pasteur, Bangui, Central African Republic

${ }^{3}$ Department of Infectious Diseases, Army Health Service, Bangui, Central African Republic

${ }^{4}$ Department of Laboratory, Hôpital de l'Amitié, Bangui, Central African Republic

${ }^{5}$ Department of Neurology, Hôpital de l'Amitié, Bangui, Central African Republic

${ }^{6}$ Faculty of Health Sciences, University of Bangui, Bangui, Central African Republic

Email address:

tekpagaspard@yahoo.com (G. Tékpa)

${ }^{*}$ Corresponding author

\section{To cite this article:}

Gaspard Tékpa, Alain Farra, Eudes Gbangba-Ngaï, Clotaire Rafaï, Jean De Dieu Longo, Fidèle Kitakossi, Pascal Mbelesso. Etiologies of Bacterial Meningitis in Context of Conflict in Central African Rural Areas. International Journal of Infectious Diseases and Therapy.

Vol. 4, No. 1, 2019, pp. 13-17. doi: 10.11648/j.ijidt.20190401.13

Received: November 11, 2018; Accepted: May 11, 2019; Published: June 11, 2019

\begin{abstract}
Bacterial meningitis is a health problem because of its high frequency and severity. They are endemic and epidemic in the Central African Republic (CAR). The objective of this work was to describe the etiologies of bacterial meningitis in the northern part of the Central African Republic. This was a retrospective descriptive study, conducted at the district hospital in Paoua, covering the period from 1 January 2011 to 30 September 2016. We included in the study, all suspected cases of meningitis (neuro-meningeal and infectious signs) confirmed by isolation of a bacterium from cerebrospinal fluid (CSF) analysis. An anonymous questionnaire collected sociodemographic and biological data that were entered and analyzed with the Epi Info7 software. We included 274 patients whose median age was six years with extremes of 6 months and 54 years. In $75 \%$ of the cases, the patients were under 9.5 years old. There were 156 men $(56.93 \%)$ giving a sex ratio of 1.32. The prevalence of HIV was $4.74 \%$ (13/274). Examination of cerebrospinal fluid (CSF) had a turbid appearance in $80.66 \%$, purulent in $7.66 \%$, clear in $6.57 \%$, hematic in $3.65 \%$ and xanthochromic in $1.46 \%$. The bacteriological examination revealed the following main germs $S$. pneumoniae in $51.82 \%, 40.15 \%$ N. meningitidis, $H$. influenzae $7.30 \%$. We found a case of E. coli $(0.36 \%)$ and Streptococcus group B $(0.36 \%)$. On an evolutionary level, the overall lethality was $14.96 \%$. This lethality rate was $20.42 \%(29 / 142)$ for S. pneumoniae, 30\% (6/20) for H. influenzae and 5.45\% (6/110) for N. meningitidis. In our study, the main causes of bacterial meningitis were $S$. pneumoniae, $N$. meningitidis and $H$. influenzae against which there are effective vaccines. Increasing immunization coverage against these germs may help to reduce the magnitude and severity of these infections.
\end{abstract}

Keywords: Bacterial Meningitis, Etiology, Paoua, Central African Republic

\section{Introduction}

Bacterial meningitis occurs worldwide, with 1.2 million cases recorded annually, 135000 of which deaths. About 500 000 of these cases and 50000 of these deaths are attributable to meningococci $[1,2]$. They are mainly caused by Neisseria meningitidis, Streptococcus pneumoniae, or Haemophilus influenzae. In children, the most common germs are Streptococcus pneumoniae and Haemophilus influenzae, two fragile germs often giving a sterile culture disrupted Cerebrospinal Fluid (CSF). Every year, epidemics of bacterial meningitis occur in a large area of sub-Saharan Africa, the meningitis belt [3]. 
In a retrospective study of 502 cases observed in 5 years in the neurology department in Bangui, the hospital prevalence of bacterial meningitis was $12.1 \%$. It occurred in $75 \%$ of cases during the dry season, between November and April, with a significant peak in March $(24.5 \%$ of cases). The microorganisms isolated were S. pneumoniae (45.2\%), $N$. meningitidis (14.5\%) and Haemophilus influenzae (1.2\%) [4]. In addition, another study neuromeningeal infections of adults in Bangui showed that pneumococcal meningitis accounted for $21.5 \%$ followed by meningococcal meningitis $5 \%[5]$.

In the Central African Republic, haemophilus and pneumococcal vaccines were introduced in the Expanded Program on Immunization (EPI) in 2008 and 2011 respectively. They are administered free of charge under the EPI throughout the country. The epidemiological surveillance system for bacterial meningitis is based on the notification of suspected or confirmed cases weekly and monthly. Meningococcal meningitis is notified immediately. Since the introduction of pneumococcal and haemophilus vaccines in EPI, a sentinel surveillance site for pediatric bacterial meningitis has been established in Bangui. The occurrence of the humanitarian crisis in the Central African Republic since the end of 2012 has disrupted the functioning of the entire health system including epidemiological surveillance. It has thus become difficult because of the insecurity of regularly having data on meningitis in rural areas where there is not security. This situation led to the implementation of this study in the locality of Paoua, located in the north of CAR in the African meningitis belt, but to our knowledge, the etiological profile of bacterial meningitis in this highly endemic area is not documented. The objective of our study was to describe the etiologies of bacterial meningitis observed at Paoua District Hospital.

\section{Materials and Methods}

We did our study in Paoua, located at 500 kilometers from Bangui in the North of CAR. In this locality, the climate has a Sahelian tendency with a long dry season of 8 to 9 months, from October to May. This was a retrospective descriptive study covered the period from 1 January 2011 to 30 September 2016 corresponding to 5 years and 9 months. The study population consisted of all patients admitted to hospital in the pediatric and adults medical departments of Paoua Hospital during the study period. We included in the study, patients admitted for meningitis confirmed by the detection of a bacterium in the CSF. At the Paoua Hospital, confirmation of the diagnosis of meningitis is based on CSF analysis which includes cytology and latex testing. The technical platform does not allow the direct examination of the CSF under the microscope or the culture with antibiogram. In case of doubt diagnosis, some samples are sent for confirmation to Bangui. For our study, the biological diagnosis of bacterial meningitis was obtained using a direct latex agglutination test (Pastorex). A single test for all bacteria (multiplex) was performed on a sample of CSF. For HIV infection, each patient had undergone a first rapid diagnostic test (Determine) followed in case of positivity by a second test (Immunocombs). Any patient who tested positive for both Determine and Immunocombs was considered HIVpositive.

The study was implemented after agreement of the ethics committee of the Faculty of Health Sciences of the University of Bangui. For each patient included, we collected data related to socio-demographic characteristics (age, sex, place of residence), associated pathologies, para-clinical data (CSF analysis, HIV serology) and the evolution cases. Data were collected from medical records using an anonymous questionnaire; these data were entered and analyzed using the Epi Info 7 software.

\section{Results}

\subsection{General Characteristics of Patients}

We included 274 patients whose analysis of the cerebrospinal fluid had revealed a germ. The median age was 6 years with extremes of 6 months and 54 years. In $75 \%$ of the cases, the patients were under 9.5 years old. There were 156 men (56.93\%) giving a sex ratio of 1.32 . The prevalence of HIV was $4.74 \%(13 / 274)$. In the antecedents of the patients, we recorded a case of pneumopathy and a case of splenectomy. There were three pregnant women $(1.1 \%)$ and one homozygous sickle cell patient $(0.36 \%)$.

\subsection{Study of the Cerebrospinal Fluid}

Examination of the cerebrospinal fluid showed a turbid appearance in $80.66 \%$, purulent in $7.66 \%$, clear in $6.57 \%$, hematic in $3.65 \%$ and xanthochromic in $1.46 \%$. The latex agglutination test revealed the following main germs $S$. pneumoniae in $51.82 \%, 40.15 \% N$. meningitidis and $H$. influenzae in $7.30 \%$. We found one case of E. coli $(0.36 \%)$ and Group B Streptococci $(0.36 \%)$.

CSF was cloudy in 121 cases $(44.16 \%)$. Table 1 describes the distribution of patients according to the bacterium and the macroscopic aspect of the CSF.

Table 1. Distribution of patients by appearance of cerebrospinal fluid and the bacterium responsible for meningitis.

\begin{tabular}{|c|c|c|c|c|c|c|}
\hline \multirow{3}{*}{ Bacterium } & \multicolumn{5}{|c|}{ Appearance of the cerebrospinal fluid } & \multirow{3}{*}{ Total } \\
\hline & clear & hematic & purulent & trouble & xanthochromic & \\
\hline & NOT (\%) & NOT $(\%)$ & NOT (\%) & NOT $(\%)$ & NOT (\%) & \\
\hline S. pneumoniae & $6(4.23)$ & $8(5.63)$ & $11(7.75)$ & $113(79.58)$ & $4(2.82)$ & 142 \\
\hline N. meningitidis & $10(9.09)$ & $1(0.91)$ & $6(5.45)$ & $93(84.55)$ & $0(0,00)$ & 110 \\
\hline H. influenzae b & $2(10.00)$ & $1(5.00)$ & $3(15.00)$ & $14(70.00)$ & $0(0,00)$ & 20 \\
\hline E.coli strain K1 & $0(0,00)$ & $0(0,00)$ & $1(100,00)$ & $0(0.00)$ & $0(0,00)$ & 1 \\
\hline Group B Steptococcus & $0(0,00)$ & $0(0,00)$ & $0(0,00)$ & $1(100,00)$ & $0(0,00)$ & 1 \\
\hline
\end{tabular}


In all age groups, $S$. pneumoniae was observed. The proportion of $H$. influenzae $b$ before the age of one year was $10.96 \%$. The distribution of patients according to the bacterium responsible for meningitis and age is described in Table 2 . The evolution of meningitis cases according to bacterial etiology is described in Figure 1.

Table 2. Distribution of patients by age and the bacterium responsible for meningitis.

\begin{tabular}{|c|c|c|c|c|c|c|}
\hline \multirow{3}{*}{ Age (years) } & \multicolumn{5}{|c|}{ Bacteria number $(\%)$} & \multirow{3}{*}{ Total } \\
\hline & E.coli $K 1$ & H. influenzae $b$ & N. meningitidis & S. pneumoniae & Group B Steptococcus & \\
\hline & Numbre (\%) & Number (\%) & Number (\%) & Number (\%) & Number (\%) & \\
\hline$<1$ & $0(0.00)$ & $8(10.96)$ & $24(32.88)$ & $41(56.16)$ & $0(0.00)$ & 73 \\
\hline $1-4$ & $0(0.00)$ & $5(8.06)$ & $28(45.16)$ & $29(46.77)$ & $0(0.00)$ & 62 \\
\hline $5-14$ & $1(1.08)$ & $5(5.38)$ & $38(40.86)$ & $48(51.61)$ & $1(1.08)$ & 93 \\
\hline $15-24$ & $0(0.00)$ & $1(5.88)$ & $9(52.94)$ & $7(41.18)$ & $0(0.00)$ & 17 \\
\hline $25-34$ & $0(0.00)$ & $0(0.00)$ & $4(36.36)$ & $7(63,64)$ & $0(0.00)$ & 11 \\
\hline$\geq 35$ & $0(0.00)$ & $1(5.56)$ & $7(38.89)$ & $10(55,56)$ & $0(0.00)$ & 18 \\
\hline
\end{tabular}

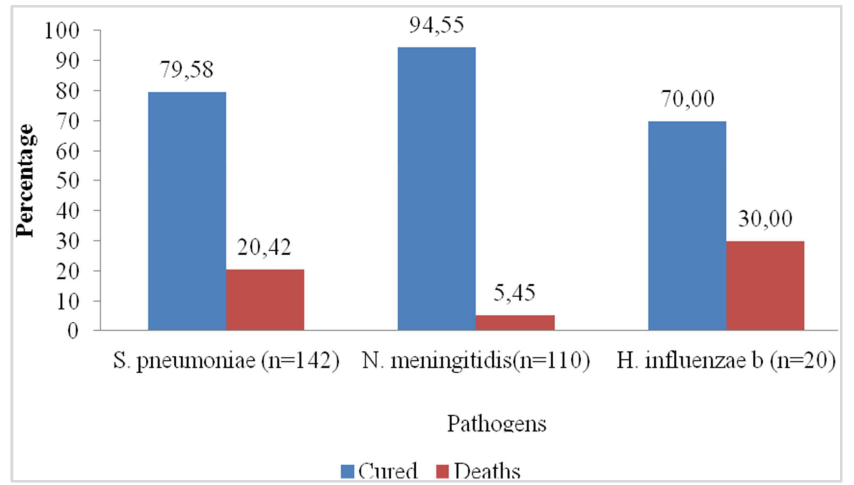

Figure 1. Morbidity and mortality related to the main bacterial meningitis agents observed in Paoua from 2011 to 2016.

\subsection{Average Length of Stay}

The average length of stay was calculated for the three main germs and was $9 \pm 5.47$ days. It was $8.15 \pm 4.60$ days for $N$. meningitidis, $8.46 \pm 4.72$ days for $H$. influenzae $\mathrm{b}$ and $9.52 \pm 6.13$ days for $S$. pneumoniae; there was no significant difference, $p=0.24$. With regard to pneumococcus, $25 \%$ of patients were hospitalized more than 13 days. Hospitalization lasted less than six days in case of meningococcus or he mophilus influenzae.

\subsection{Complications and Sequelae}

We recorded a total of 21 complications and sequelae which corresponds to a rate of $9.13 \%$ (21/230). This frequency was $13.64 \%$ (15/95) for S. pneumiae, $12.50 \%$ $(2 / 14)$ for $H$. influenzae and $3.85 \%$ (4/104) for $N$. meningitidis. The sequelae were of neurological origin in all cases; they resulted in language disorders (dysarthria, aphasia), in three cases $3 / 21$ or $14.28 \%$ of sequelae, neurological deficits (hemiplegia, paraplegia, facial paralysis), or $28.56 \%$, tone disorders (axial hypotonia) is $4.76 \%$, sphincter disorders (urinary incontinence). in $4.76 \%$ of cases or dysphagia $(4.76 \%)$. The different types of complications and sequelae observed are summarized in Table 3.

Table 3. Complications and sequelae of bacterial meningitis according to the germs.

\begin{tabular}{lllllllll}
\hline & \multicolumn{2}{l}{ Complications / sequelae } & & \\
\cline { 2 - 8 } Bacterium & Aphasia & Epilepsy & dysarthria & Hemiplegia & paraplegia & $\begin{array}{l}\text { facial } \\
\text { paralysis }\end{array}$ & $\begin{array}{l}\text { Axial } \\
\text { hypotonia }\end{array}$ & $\begin{array}{l}\text { Urinary } \\
\text { dysphagia } \\
\text { incontinence }\end{array}$ \\
\hline H. Influenzae b & 0 & 2 & 0 & 0 & 0 & 0 & 0 & 0 \\
N. meningitidis & 0 & 1 & 0 & 1 & 1 & 0 & 0 & 0 \\
S. pneumoniae & 2 & 6 & 1 & 2 & 1 & 1 & 1 & 1 \\
Total & 2 & 9 & 1 & 3 & 2 & 1 & 1 \\
\hline
\end{tabular}

\section{Discussion}

Bacterial meningitis affects all age groups with predominance in children under 10 years of age. This is reflected in our study by a median age of six. The young age found in our series has been reported by several authors in Bangui in the Central African Republic. The high prevalence of bacterial meningitis in the young Central African child has been described in Bangui, by Bercion et al and Clouzeau et al who found an average age of 17 months and four years respectively $[6,7]$. Outside CAR, the prevalence of bacterial meningitis in children has been reported in Ivory Cost and
Tunisia $[8,9]$. The male predominance observed in our work is reported by several African authors [4, 5, 10]. HIV prevalence among patients with bacterial meningitis is high and is closer to the national prevalence of $4.9 \%$ according to the 2010 Multiple Indicator Survey [11]. The 15 to 24 age group is the most affected by HIV infection, this would be related to the precocity of sexual intercourse, the low socioeconomic level characterized by a low level of education (lack of information on HIV) and poverty. Our data are similar to findings from previous studies in Bangui $[4,5,12]$.

Germs were highlighted in the CSF regardless of the macroscopic appearance. CSF can be clear at the beginning of purulent meningitis [13]; this was confirmed in our study 
with $6.57 \%$ clear CSF. In the vast majority of cases, the fluid was turbid or purulent identical to that of Raobijaona et al [14]. The purulent or turbid character of CSF in our patients could be explained by late resort to care. Financial difficulties, the use of traditional healers, self-medication or transport difficulties, all aggravated by insecurity, are factors behind this delay in access to care.

In this study, pneumococcus (51.82\%) and meningococcus $(40.15 \%)$ are the main agents responsible for meningitis. Studies in Bangui have returned to the same trend confirming evidence in the literature that pneumococcus is the most common bacterial meningitis agent in adults and young children outside outbreaks of meningococcal meningitis [5, 7, 12, 13]. However, a different etiological profile was described in Bangui in a pediatric environment in 2007 with $48 \%$ pneumococcus and $35 \%$ haemophilus [6]. This situation corresponds to a period prior to the introduction of pneumococcal and haemophilus vaccines into the Central African EPI. The introduction of these two vaccines would have led to a reduction in the frequency of Haemophilus infections in favor of those caused by meningococcus, while the pneumococcus remains in the foreground. Prior to the introduction of $H$. influenzae vaccine in the EPI, this germ was the second most common cause of purulent meningitis in children, according to several African authors [6, 14, 15].

On an evolutionary level, the overall lethality was $14.96 \%$. The highest lethality was observed in S. pneumoniae meningitis (20.42\%). This global lethality seems low compared to that found in years prior to Bangui in adults and pediatric which was respectively $31.9 \%$ and $35 \%$ [6].

The high incidence of sequelae observed in our study is related in part to late management. The sequelae were in all cases of neurological nature and the manifestations were very variable with a predominance of motor deficit followed by language disorders. Most sequelae were observed in patients with pneumococcal meningitis. The adverse evolution of acute bacterial meningitis in developing countries is common. Neurological complications can affect up to $25 \%$ of patients [16]. In Africa, bacterial meningitis is associated with high lethality and a high risk of neurological sequelae. S pneumoniae and $\mathrm{H}$ influenzae $\mathrm{b}$ are responsible for approximately one-third lethality and a quarter of clinically evident sequelae in survivors [17].

\section{Conclusion}

Bacterial meningitis are common in the Central African Republic and predominates in children. The main causative organisms are S. pneumoniae $\mathrm{N}$. meningitidis and $\mathrm{H}$. influenzae. It is therefore necessary to strengthen prevention through information, education and communication on these illnesses and to improve the implementation of routine immunization under the EPI

\section{Conflicts of Interest}

The authors declare that they have no competing interests.

\section{References}

[1] World Health Organization. Emergence de la méningococcie W135. Rapport d'une consultation de l'OMS; Genève, 2001 WDC/CSR/GAR/2002.

[2] World Health Organization. Relevé épidémiologique hebdomadaire. $2013, \quad 12: \quad 88, \quad 129-36$. Http://www.who.int/wer.

[3] World Health Organization. Activités de surveillance et de réponse à la méningite épidémique pour la saison 2002-2003 dans les pays de la ceinture africaine. Rapport d'une consultation informelle de l'OMS; Genève 2003. $\mathrm{WHO} / \mathrm{CDS} / \mathrm{CSR} / \mathrm{GAR} / 2003.13$

[4] Mbelesso P, Tatangba-Bakozo A, Fikouma V. Les méningites bactériennes de l'adulte en milieu hospitalier centrafricain. Bull Soc Pathol Exot, 2006, 99 (4): 261-263.

[5] Yassibanda S, Kamalo CG, Mbolidi CD, Koffi B, Camengo SP et al. - Les infections neuroméningées de l'adulte en milieu hospitalier à Bangui: Aspects étiologiques, cliniques et évolutifs. Méd Afr Noire, 2002; 49: 299-303

[6] Bercion R, Bobossi-Sérengbe G, Gody JC, Beyam EN, Manirakiza A, Le Faou A. Acute Bacterial meningitidis at the complexe pédiatric of Bangui, Central African Republic. Journal of Trop Ped. 54 (2): 125-128.

[7] Clouzeau J, Matera D, Bobossi G. Étiologies des méningites chez les enfants traités au complexe pédiatrique du CNHU de Bangui, République Centrafricaine, 1996. In. Treizièmes rencontres franco-africaines de pédiatrie, 1999. Faculté de médecine de Paris, France, A135-49.

[8] Faye-Ketté H, Doukou ES, Boni C, Akoua-Koffi C, DialloTouré K, Kacou-N'Douba A, Bouzid S, Dossso M, TimitéKonan M. Agents des méningites purulentes communautaires de l'enfant tendance épidémiologique à Abidjan, de 1995 à l'an 2000. Bull Soc Pathol Exot, 2003; 96 (4): 313-316.

[9] Ben Haj Khalifa A, Mastouri M, Ben Abdallah H, Noomen S, Kheder M. Les méningites purulentes dans la région de Monastir, Tunisie (1999-2006): aspects bactériologiques et état de résistance aux antibiotiques. Bull. Soc. Pathol. Exot, 2011; 104 (1): $42-49$

[10] Nguefack S, Chiabi A, Enoh J, El HadjiDjouberou, Mah E, KengneKamga K, Tatah S, Mbonda E. Etiologies and Outcome of Children with Purulent Meningitis at the Yaoundé Gyneco-Obstetric and Pediatric Hospital (Cameroon). Open Journal of Pediatrics, 2014; 4: 269-75.

[11] Central African Institute of Statistics and Economic and Social Studies. Enquête par grappes à indicateurs multiples MICS RCA 2010, Rapport final. Bangui, RCA ICASEES.

[12] Békondji C, Bernede C, Passone N, Minssart P, Kamalo C, Mbolidi D, Germani Y. Primary and opportunistic pathogens associated with meningitis in adults in Bangui, Central African Republic, in relation to human immunodeficiency virus serostatus. International journal of infectious diseases, 2006; 10: 387-95.

[13] College of Infectious and Tropical Disease Academics. Maladies infectieuses tropicales. e-Pilly Trop 2012, édition alinéa plus, $995 \mathrm{p}$. 
[14] Raobijaona H, Rabesandratana N, Razanamparany M, Migliani R, Pfister P, Roux JF. Les méningites aiguës bactériennes du nourrisson observées au Service de Pédiatrie A de Befelatanana, Centre Hospitalier Universitaire d'Antananarivo (Madagascar). Arch Inst Pasteur Madagascar 1999; 65 (2): 70.

[15] Razafindralambo M, Ravelomanana N, Randriamiharisoa FA, Migliani R, Clouzeau J, Raobijaona H, Rasamoelisoa J, Pfister P. Haemophilus influenzae, deuxième cause des méningites bactériennes de l'enfant à Madagascar. Bull Soc Pathol Exot, 2004; 97 (2): 100-103.
[16] Aku FY, Lessa FC, Asiedu-Bekoe F, Balagumyetime P, Ofosu W, Farrar J, Ouattara M, Vuong JT, Issah K, Opare J, Ohene SA, Okot C, Kenu E, Ameme DK, Opare D, Abdul-Karim. Meningitis Outbreak Caused by Vaccine-Preventable Bacterial Pathogens - Northern Ghana, 2016. Morb Mortal Wkly Rep. 2017; 66 (30): 806-810. doi: 10.15585/mmwr.mm6630a2

[17] Ramakrishnan M, Ulland AJ, Steinhardt LC, Moïsi JC, Were F, Levine OS. Sequelae due to bacterial meningitis among African children: a systematic literature review BMC Medicine 2009, 7: 47 http://www.biomedcentral.com/17417015/7/47. 